a general complex of change that can be initiated by lesions or disturbances which bear no specific relation to either structure. Here it is the essential absence of controls, or of experiments that are carefully designed to test specific hypotheses, which prevents the student from coming to grips with the problems of the hypothalamus. Prof. Harris might have been better advised, therefore, if he had left the problem with the statement, which appears at the start of the general discussion to this section of the book, that the "information as to the details of the mechanism involved is scanty", instead of proceeding to speculations about the number of chemotransmitters that might be involved (when not even a single one has yet been identified), and about the functional differentiation of individual portal vessels in relation to different areas of the anterior pituitary (when it is not yet known that the number, let alone the precise disposition, of the portal vessels in a given species is constant). But if Prof. Harris does not tell us on what "good grounds" he bases this speculation, equally he does not refer properly to experiments that have conclusively shown that whatever influence the hypothalamus exercises over the functions of the anterior pituitary, the pituitary-portal vessels are neither a sufficient nor a necessary explanation of this presumed "control".

Theorizing from slender fact is, of course, one of the ways new fields of biological knowledge develop. But, as in this case, there is always the risk that a single positive observation may emerge which completely undermines an edifice of speculation, and particularly one that has been erected because of an urge to explain the incomprehensible. Publication is these days not infrequently slow, and the danger of a scientific work being somewhat out of date was accentuated in the present case by the fact, noted in the preface, that the book was based on a series of lectures given a few years back.

S. ZUCKERMAN birds for a book; but one wonders whether this early plunge was in fact good for "L.A.G.", for as an artist he was not mature, and then, as now, the influence of Audubon was a dominant one in American bird portraiture. Had he been granted a few more years of study, it is possible that he would have become aware of the Swedish painter of birds and animals, his contemporary Bruno Liljefors, with his very different asthetic approach to the work. But, as this book reveals, poor Louis was either so inundated with work of a semi-scientific nature or was away on his travels in foreign parts in search of specimens, that he had no time for artistic experiments, and his style remained, in its essence, a linear one. Because of the dictates of his scientist-patrons his colour did not equal his draughtsmanship, and in spite of all the talk and furore about the effect of light on the plumage of birds, he was forced to present his subjects in a light which was acceptable to the scien. tist and not in that which emanates from the Sun.

The book is particularly interesting in its account of the hunting expeditions into which "L.A.G." entered with so much zest and excitement, and in which he suffered heat, cold, weariness and illness, meantime killing a prodigious number of birds; these, however, were not wasted, for, fulfilling the purpose for which they were intended, they eventually found their way into museums as mounted specimens or study skins. Interesting too are the letters describing his adventures in landscape painting, these paintings being the preliminary studies for the landscape backgrounds to the dioramas in the American Museum of Natural History.

'Ars longa, vita brevis'; especially was this so in the case of "L.A.G.", for his tragically sudden death occurred while he was still at the height of his powers.

C. F. TUNNICLIFFE

\section{PRESTRESSED CONCRETE DESIGN}

\section{ARTIST VERSUS SCIENCE}

\section{Louis Agassiz Fuertes}

Edited by Mary Fuertes Boynton. Pp. xviii $+317+17$ plates. (London and New York: Oxford University Press, 1956.) 45s. net.

$T$ $O$ readers who are familiar with the paintings of Louis Agassiz Fuertes, especially those of us who are either painters, naturalists or ornithologists, this book holds much of absorbing interest. But as 'much will have more', it is probable that the need will be felt for additional illustrations to those few given in the book, excellent as they are; especially of those swift field studies and preliminary drawings which are always more intimate and spontaneous, more of the very essence of the artist, than the deliberately planned, finished works.

This book consists mainly of letters from "L.A.G." to his friends and business connexions, and of theirs to him, these being supported, where necessary, by biographical notes. Together they paint a fairly full portrait of the artist, who emerges as a charming, sociable, hard-working person, with a great fund of humour, and obviously beloved by all who knew him.

In a way he was lucky, in that his work was recognized and taken up when he was quite young. He was commissioned by no less an ornithologist than Elliot Coues to paint one hundred illustrations of
The Theory of Prestressed Concrete Design Statically Determinate Structures. By Prof. Henry J. Cowan. Pp. xvii + 264. (London: Macmillan and Co., Ltd.; New York : St. Martin's Press, Ine., 1956.) 36s. net.

7 HE title of Prof. H. J. Cowan's book is rather misleading, since it concerns itself almost entirely with beams, with just $12 \frac{1}{2}$ pages devoted to pipes and tanks. It can scarcely be said to deal comprehensively with statically determinate structures in general. So far as statically determinate beams are concerned, the book has been written with great care and thoroughness, with numerous worked examples to illustrate points in the text when dealing with design, after a general approach through early chapters on fundamental principles, manufacture, and the properties of steel and concrete.

It is a debatable point whether prestressed concrete design should be carried out these days using working stresses and working loads, with subsequent checks on the load factor at cracking, and at failure. However, having accepted this principle, which permits constant values of Young's modulus for steel and for concrete at the design stage, and permits tonsion in the concrete, one can appreciate the methods used to get balanced designs for a number of different cases of increasing complexity, and the neat use of diagrams to indicate the range of practical solutions. 